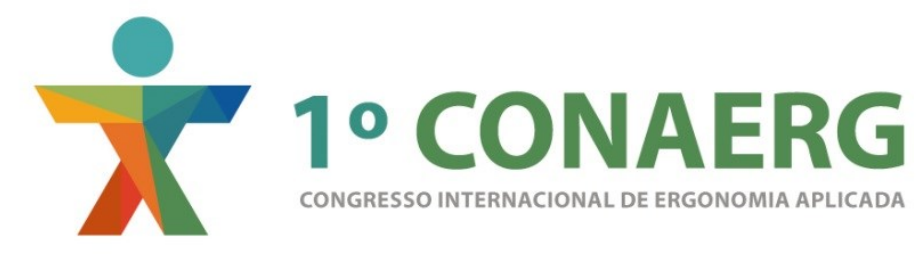

\title{
GESTÃO DE UM PROGRAMA DE PREVENÇÃO DAS LER/DORT EM UMA REDE DE SUPERMERCADOS: UM RELATO DE EXPERIÊNCIA
}

\author{
João Luiz de Alencar Pandolphi (1); \\ Emily de Fátima Lima Vasconcelos (2); \\ lassiara de Araújo Dantas Lima de Almeida (3);
}

(1) Faculdade Estácio, InVita Ergonomia, Mestre em Saúde Coletiva, Fisioterapeuta do Trabalho

e-mail: jpandolphi@hotmail.com

(2) InVita Ergonomia, Mestre em Atividade Física Adaptada

e-mail: emilyfisio@hotmail.com

(3) InVita Ergonomia, Supervisora técnica, Fisioterapeuta do Trabalho

e-mail: iassiara@hotmail.com

\begin{abstract}
RESUMO
Trata-se de um estudo descritivo de um relato de experiência da gestão da fisioterapia do trabalho e ergonomia de uma empresa prestadora de serviços em uma rede de supermercados visando a prevenção de LER/DORT. As ações na empresa possuem foco preventivo, mas também atuando na reabilitação quando necessário. São realizados serviços de ginástica laboral, orientação postural, treinamentos, análise ergonômica e atendimentos fisioterapêuticos em ambulatório. A rede de supermercado contempla 9 lojas em Nata-RN e região metropolitana, com um total de 2700 colaboradores. São seis fisioterapeutas, sendo quatro operacionais atuando diretamente nas lojas, uma fisioterapeuta supervisora, e um coordenador, responsável pela gestão e acompanhamento do serviço. Neste artigo foram abordados dados referentes ao mês de junho de 2016, com descrição quantitativa dos serviços realizados, bem como reflexões quanto as barreiras e facilitadores da aplicabilidade das ações.
\end{abstract}

\section{ABSTRACT}

This is a descriptive study of an experience report of work physiotherapy management and ergonomics of a service company in a supermarket chain aimed at preventing RSI / MSDs. Shares in the company have preventive focus, but also working in rehabilitation when needed. gymnastics services, postural orientation, training, ergonomic analysis and physical therapy care in ambulatory are performed. The supermarket network has nine stores in Christmas-RN and the metropolitan area, with 2700 employees. Six physiotherapists, four operating working directly in the shops, a physiotherapist supervisor and a coordinator, responsible for managing and monitoring service. In this article, we were addressed data for the month of June 2016, with a quantitative description of the services performed, as well as reflections as the barriers and facilitators of the applicability of the shares. 


\section{INTRODUÇÃO}

As principais ações propostas no campo da prevenção e controle das doenças ocupacionais levam em conta a possibilidade da promoção da saúde no ambiente de trabalho, determinando as condições de risco, a caracterização e a quantificação dos fatores de risco, atingindo as empresas, os órgãos públicos e o mercado informal. As intervenções preventivas realizadas atualmente trabalham com um grupo de atividades centradas nos indivíduos, como a ginástica laboral, os exercícios de pausa compensatória, as correções posturais in loco e os treinamentos de manejo de peso. Ressalta-se a necessidade dos cuidados com o corpo não somente no trabalho, mas também fora dele (RIESCO, SANDOVAL, KAPPES 2006).

Dentre diversas categorias profissionais afetadas pelas doenças osteomusculares, estão os funcionários de diversos setores de um supermercado. A incidência de DORT, por exemplo, é comum nos operadores de caixas de supermercado (checkout). Nessa categoria profissional, a DORT está relacionada, geralmente, à introdução de novas tecnologias, como a informática e a leitura óptica, sem a adaptação dos postos e do ritmo de trabalho à nova situação. De acordo com o Bureau of Labor \& Statistics, em 2003, havia mais de 20 mil distúrbios osteomusculares em trabalhadores de supermercados nos Estados Unidos. Mais de $50 \%$ dessas lesões musculoesqueléticas estavam relacionadas ao levantamento de materiais nas lojas (repositores). Pensando nisso, foi elaborado pelo Ministério do Trabalho o anexo 1 da NR 17, com o objetivo de estabelecer parâmetros e diretrizes mínimas para adequação das condições de trabalho dos operadores de checkout, visando à prevenção dos problemas de saúde e segurança relacionados ao trabalho.

O objetivo deste trabalho é relatar a experiência de uma empresa prestadora de serviços de fisioterapia do trabalho e ergonomia em uma rede de supermercados, expondo as barreiras e facilitadores da execução dos serviços. Além de descrever e quantificar as ações da empresa realizada nas lojas expondo as dificuldades encontradas pela equipe durante as ações e ainda sugerir possibilidades de correção dos problemas encontrados.

\section{METODOLOGIA}

Trata-se de um estudo descritivo de um relato de experiência da fisioterapia do trabalho em uma rede de supermercados onde as ações realizadas envolvem as três esferas de atenção à saúde, nesse caso, saúde do trabalhador. Possui foco preventivo, porém também atua na reabilitação, abrangendo os serviços de ginástica laboral, blitz postural, treinamentos, análise de risco ergonômico e atendimentos fisioterapêuticos em ambulatório de fisioterapia na empresa. A rede de supermercado contempla 9 lojas em Nata-RN e região metropolitana mais a central logística e administrativa, com um total de 3000 colaboradores. A equipe de fisioterapia é composta por seis fisioterapeutas, sendo quatro operacionais atuando diretamente nas lojas, uma fisioterapeuta responsável por supervisionar e gerar relatórios, e um fisioterapeuta coordenador, responsável pela gestão e acompanhamento do serviço. Neste estudo serão abordados dados referentes ao mês de junho de 2016, com descrição quantitativa dos serviços realizados, bem como reflexões quanto as barreiras e facilitadores de sua aplicabilidade. E ainda acompanhamento do número de atestados CID-M (doenças musculoesqueléticas) apresentados no período de setembro de 2014 à junho de 2016.

\section{RESULTADOS E DISCUSSÃO}

Dos serviços realizados nas lojas, destacam-se a ginástica laboral, as orientações posturais e ergonômicas (blitz postural) e os atendimentos e acompanhamentos individuais dos 
colaboradores. Além destes já citados, realizamos também treinamentos de ergonomia (ANEXO 01 NR 17) e treinamento de manuseio e levantamento de carga.

A ginástica laboral é uma as principais ações preventivas realizadas nas lojas, tendo no mês de junho atingido 1811 colaboradores, sendo a loja 8 a que atingiu um maior percentual de participação. Tal fato pode se justificar pelo maior acompanhamento do gerente de loja junto aos serviços de fisioterapia. Já nas lojas com menor percentual de participação, a principal dificuldade relatada é a falta de local para realização da atividade, além da pouca cobrança dos gestores.

\section{Gráfico 1 - Percentual de participação dos colaboradores na ginástica laboral por loja}

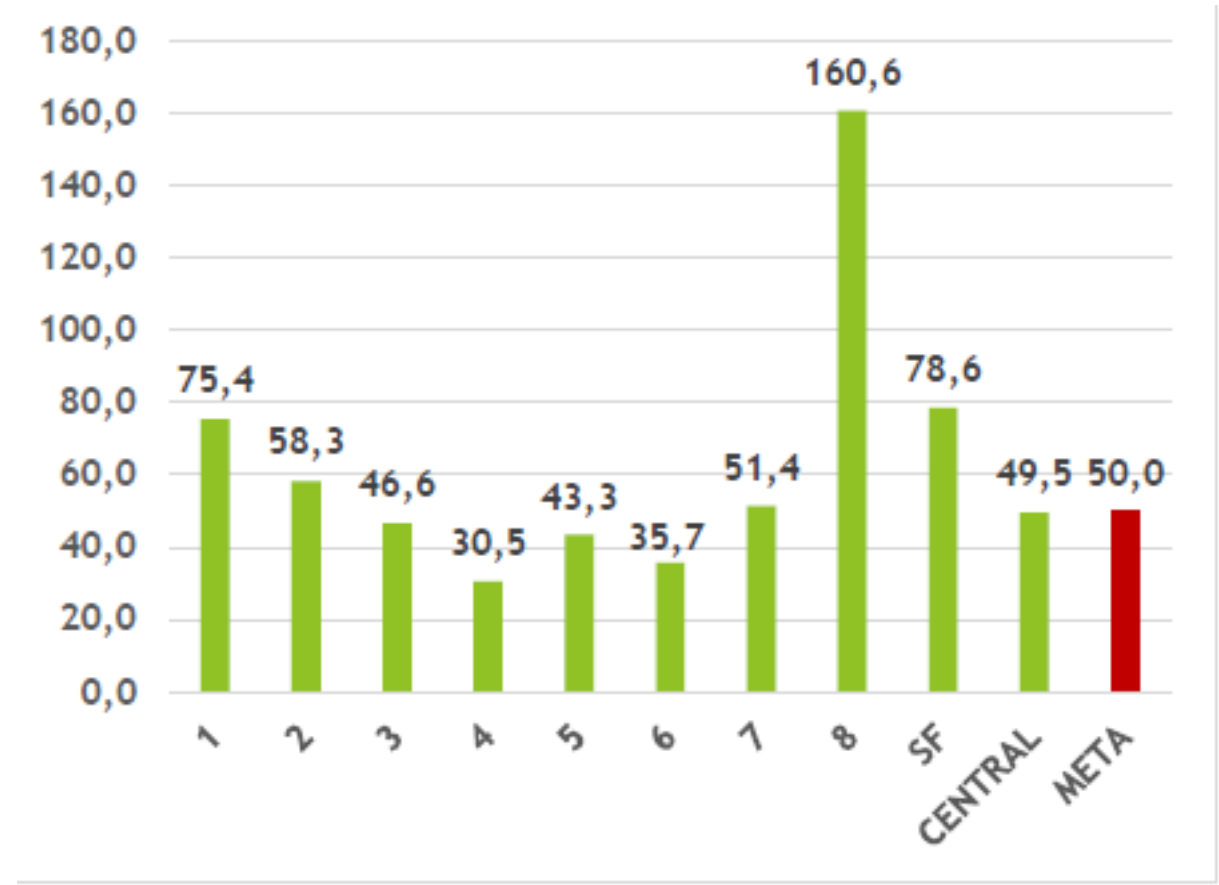

Fonte: Relatórios InVita - junho/2016

Em relação as orientações posturais e ergonômicas (blitz postural), temos uma maior facilidade no desenvolvimento desta atividade quando comparada à ginástica laboral, uma vez que o fisioterapeuta que se desloca para o posto de trabalho do colaborador, não dependendo de liberação do colaborador pelo gerenciador. Nessa atividade são realizadas orientações posturais e ergonômicas quanto ao modo operatório da função exercida, além da identificação dos riscos ergonômicos existentes no posto de trabalho do colaborador.

Gráfico 2 - Percentual de realização de orientações posturais e ergonômicas por loja 


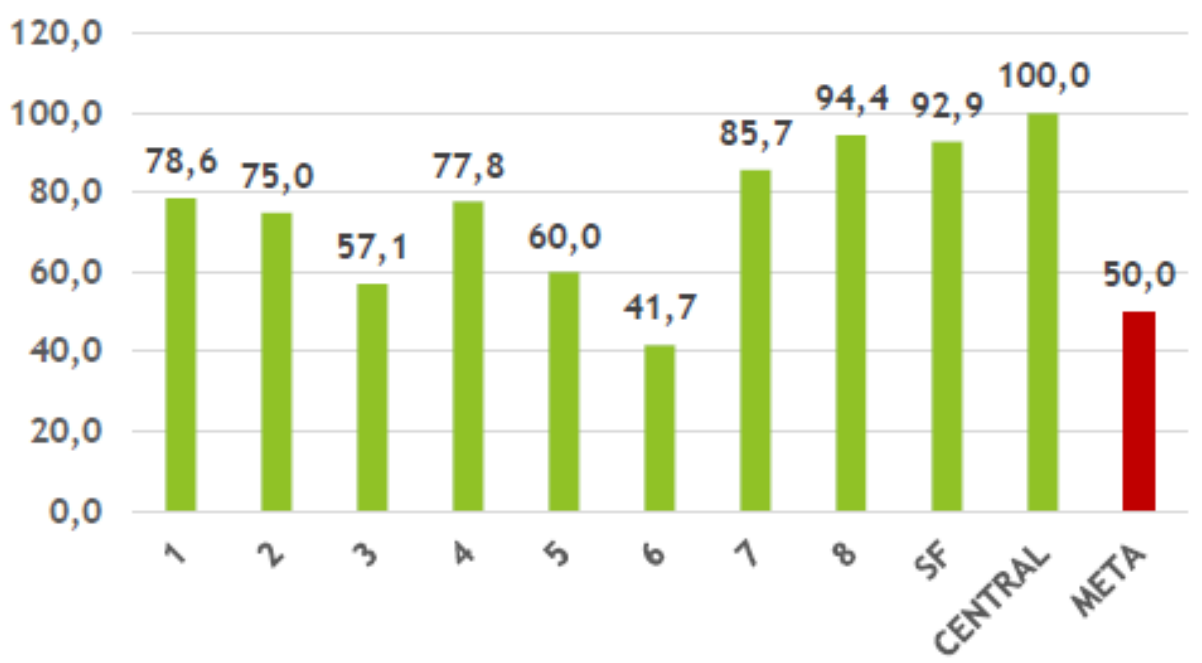

Fonte: Relatórios InVita - junho/2016

Quanto aos atendimentos ambulatoriais o colaborador é encaminhado pelo setor médico que solicita a fisioterapia, onde são realizados os tratamentos fisioterapêuticos conforme quadro clínico do colaborador. A loja 08 se destaca com atendimentos a um maior número de colaboradores. 295 colaboradores estiveram em acompanhamento no mês de junho, conforme observa-se no gráfico abaixo.

\section{Gráfico 3 - Número de atendimentos da fisioterapia por loja}

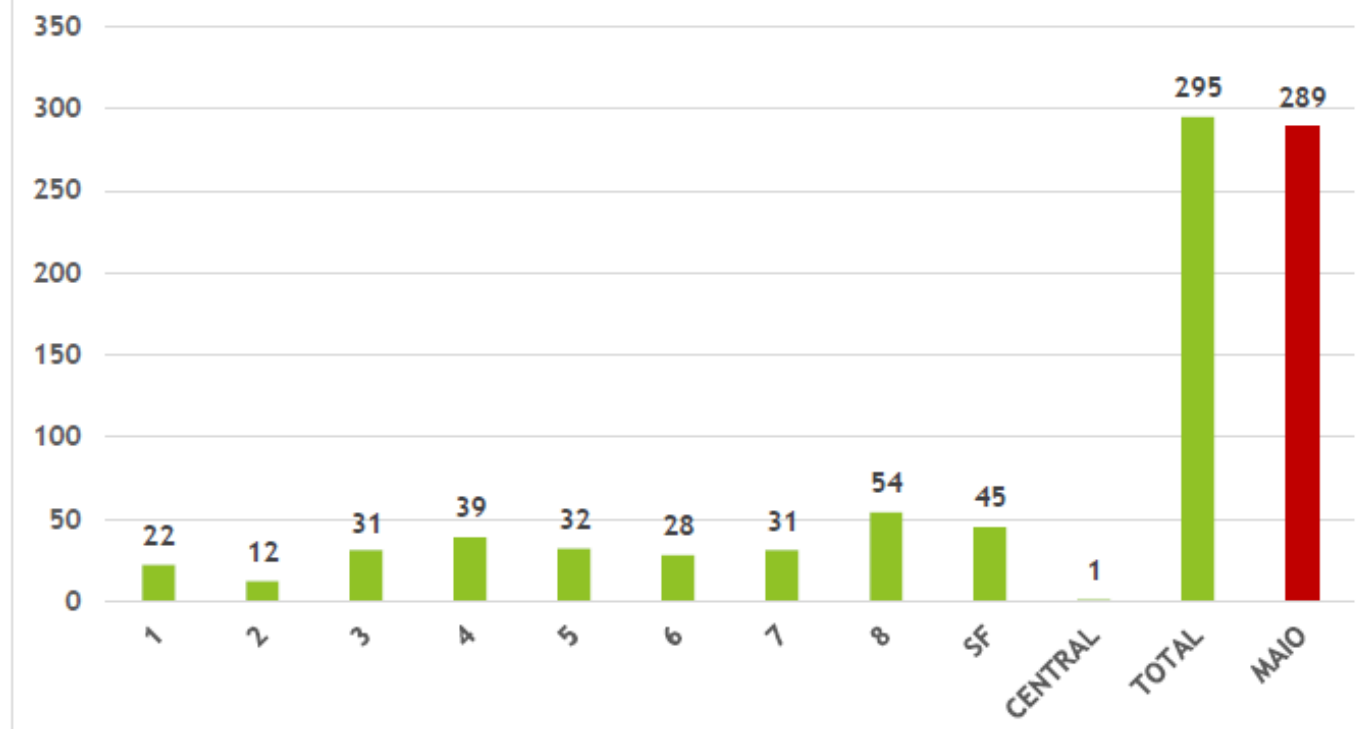

Fonte: Relatórios InVita - junho/2016

E por fim, no gráfico abaixo podemos observar um comparativo de emissão de atestados CID-M (doenças músculoesqueléticas) do período compreendido entre setembro de 2014 até junho de 2016. Foi a partir de setembro de 2014 que o serviço de fisioterapia do trabalho e ergonomia foi implantado na rede de supermercados. O gráfico aponta uma diminuição do número de atestados CID-M. 
Gráfico 4 - Número de atestados CID-M por mês.

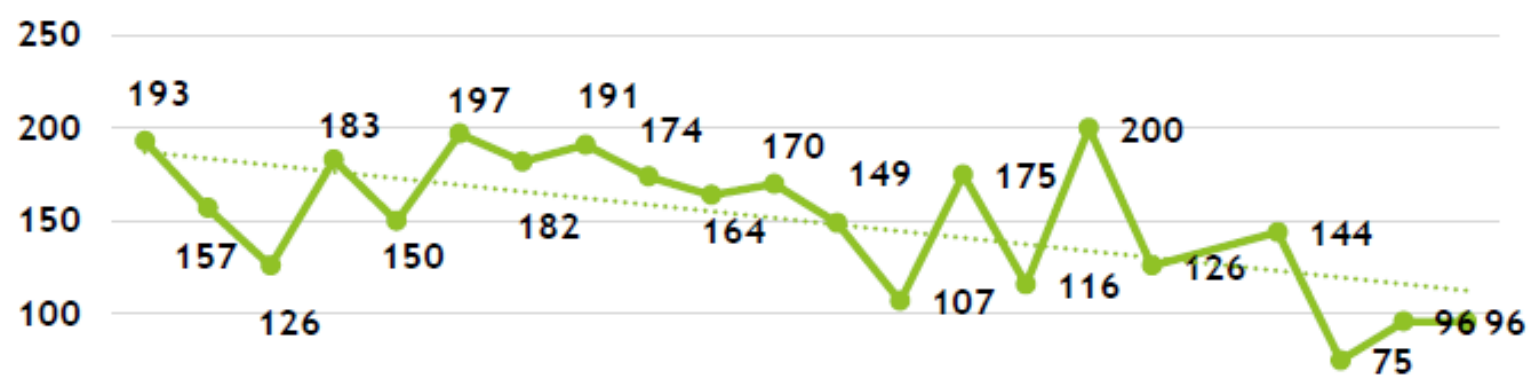

50

0

\section{雍}

Fonte: Relatórios InVita - junho/2016

\section{CONCLUSÃO}

Tal experiência tem nos permitido refletir a importância de fisioterapia e ergonomia no ambiente laboral nas três esferas de atenção à saúde, bem como acompanhamento das queixas musculoesqueléticas e ainda a aplicabilidade dos diversos serviços, ferramentas e recursos na realidade de uma rede de supermercados. Podemos concluir que as ações realizadas contribuem para a diminuição do número de atestados CID-M (Doenças muscuoesqueléticas) na empresa, ajudando consequentemente na prevenção dessas patologias. Portanto, para uma maior efetividade nas ações é necessária participação e engajamento dos gestores da empresa, bem como conscientização dos colaboradores para realizar as orientações propostas e cuidar de sua saúde também fora da empresa.

\section{REFERÊNCIAS BIBLIOGRÁFICAS}

Al-Eisa E, Buragadda S, Shaheen AAM, Ibrahim A, Melam GR. Work related musculoskeletal disorders: causes, prevalence and response among egyptian and saudi physical therapists. Middle-East J. Sci. Res. 2012;12(4):523-

BRASIL, Ministério do Trabalho e Emprego. Ergonomia - NR-17. Diário Oficial da União, Brasília, DF, 1978.Disponível:< http://www.nersat.com.br/legislacao-sobre-ergonomia-saude-e-seguranca-dotrabalho/nota-tecnica-060-2001/>. Acesso: 06 mai 2016.

BRASIL. Ministério do Trabalho e Emprego. Portaria SIT n. 08, de 30 de março de 2007. Aprova o Anexo I da NR-17 - Trabalho dos Operadores de Checkout. Diário Oficial da República Federativa do Brasil, Brasília, DF, 02 abril 2007.Disponívelem: http://www.mte.gov.br/legislacao/normas_regulamentadoras/nr_17_anexo1.pdf Acesso: 07 mai 2016. 
CLARKE CM. Workplace injuries and illnesses in grocery stores. Compensation and Working Conditions. Washington: Department of Labor, Bureau of Labor Statistics; 2003. p.1-12.

RIESCO TB, SANDOVAL RA, KAPPES V. Exercícios compensatórios laborais nos operadores de checkout" de um supermercado de Goiânia. Lect Educación Fís Deportes. 2006;10(92):26.

Settimi MM, Almeida IM, Toledo LF, Paparelli R, Silva JÁ, Martins M. Lesões por Esforços Repetitivos (LER)/Distúrbios Osteomusculares relacionados ao trabalho (DORT). São Paulo: CEREST; 2000

Silva BAM, Silva RN, Carlos FP, Grecco LAC, Grecco LH. Distúrbios osteomusculares autorreferidos em funcionários de supermercado. Rev Bras Promoç Saúde, Fortaleza, 27(1): 1320, jan./mar., 2014

Yeng LT, Teixeira MJ, Romano MA, Picarelli H, Settimi MM, Greve JMA. Distúrbios ósteomusculares relacionados ao trabalho. Rev Med. 2001;80(Ed. Esp. Pt.2):422-42. 